\title{
HisTóRIAS EM QUADRINHOS NO PROCESSO DE APRENDIZADO: DA TEORIA À PRÁTICA
}

\section{COMICS IN THE LEARNING PROCESS: FROM THEORY TO PRACTICE}

\author{
Roberto Elísio dos Santos \\ Jornalista, com doutorado e pós-doutorado em Comunicação - ECA-USP; \\ Vice-coordenador do Observatório de Histórias em Quadrinhos - ECA-USP; \\ Professor da Escola de Comunicaçáo e do \\ Programa de Mestrado em Comunicação - USCS. \\ São Caetano, SP - Brasil. \\ roberto.elisio@uscs.edu.br \\ Waldomiro Vergueiro \\ Doutor em Ciências da Comunicaçáo e \\ Professor titular da Escola de Comunicaçóes e Artes - ECA-USP; \\ Coordenador do Observatório de Histórias em Quadrinhos - ECA-USP. \\ São Paulo, SP - Brasil. \\ wdcsverg@usp.br
}

Resumo: Após décadas de rejeição por parte dos educadores, no final dos anos 1990 as histórias em quadrinhos começaram a conquistar seu espaço nas salas de aula brasileiras. No entanto, apesar dos avanços conseguidos, ainda é preciso adequar as aplicaçóes possíveis deste produto cultural às necessidades do processo de aprendizado. Nesse sentido, neste artigo temos por objetivo fomentar e nortear o uso apropriado das narrativas sequenciais nas práticas educativas, discutindo os possíveis caminhos para sua implementaçáo.

Palavras-Chave: Educação. Histórias em quadrinhos. Práticas educativas.

Abstract: After decades of rejection by the educators, comics began to conquer their place in the Brazilian classrooms in the lateig9os. However, despite the progress achieved, it is still necessary to adjust the possible applications of this cultural product to the needs of the learning process. In this sense, this article aims to encourage and guide the appropriate use of sequential narratives in the educational practices, discussing possible ways to implement them.

Key words: Comics. Education. Educational practices. 


\section{Introduçáo}

A data de 1996 é um marco importante para a trajetória de aceitação das histórias em quadrinhos como ferramenta pedagógica no Brasil. Nesse ano ocorreu a promulgação da Lei de Diretrizes e Bases da Educaçáo Nacional (LDB) que, de certa forma, propunha um pacto entre este produto cultural midiático e a educação formal. Nesse sentido, ela "[...] já apontava para a necessidade de inserção de outras linguagens e manifestaçôes artísticas nos ensinos fundamental e básico". (VERGUEIRO; RAMOS, 2009, p. Io)

De fato, a relação entre quadrinhos e educação nem sempre foi amigável, passando por momentos de grande hostilidade e outros de tímida cumplicidade, quando alguns professores mais ousados se atreveram a utilizá-los em sala de aula. Tratava-se de aplicações esporádicas, marcadas muito mais pela ousadia e entusiasmo de seus propositores do que propriamente por correção metodológica.

Djota Carvalho (2006, p. 32) documenta o início do estranhamento entre os quadrinhos e o ambiente escolar no Brasil:

Aqui no Brasil, já em 1928, surgiram as primeiras críticas formais contra as historinhas: a Associação Brasileira de Educadores (ABE) fez um protesto contra os quadrinhos, porque eles "incutiam hábitos estrangeiros nas crianças". Na década seguinte, em 1939, diversos bispos reunidos na cidade de São Carlos (SP) deram continuidade à xenofobia, propondo até mesmo a censura aos quadrinhos, porque eles traziam "temas estrangeiros prejudiciais às crianças.

Pode-se dizer que os educadores brasileiros já antecipavam algumas das críticas feitas aos quadrinhos em países da Europa (FREMION; JOUBERT, cI989), embora não fossem tão longe quanto pôde ser presenciado durante o auge da rejeiçáo aos quadrinhos, que ocorreu nos Estados Unidos, na década de 1950, com a publicação do livro Seduction of the Innocent (Sedução do inocente), do psiquiatra Fredric Wertham (apud NYBERG, 1998), que trabalhava com menores infratores. A visão desse autor, exageradamente crítica à cultura de massa, levou pais e professores a 
queimar revistas nos pátios das escolas, enquanto que os editores, para impedir a censura oficial e reverter a queda nas vendas, tiveram que criar um Código de Ética para suas publicaçôes (BEATY, 2005; NYBERG, I998).

Com o tempo, contudo, os conflitos entre histórias em quadrinhos e educação foram se amenizando. A partir dos anos I970, já era possível encontrar narrativas gráficas sequenciais em livros didáticos brasileiros, elaboradas por artistas consagrados, como Eugenio Colonnezze ou Rodolfo Zalla (1992). Esses quadrinhos sintetizavam ou exemplificavam, em uma ou mais vinhetas, o conteúdo do tópico ou do capítulo. Utilizando a linguagem característica dos quadrinhos (balóes de fala, recordatórios etc.), estes eram usados para suavizar a diagramação e complementar de forma mais leve o texto didático.

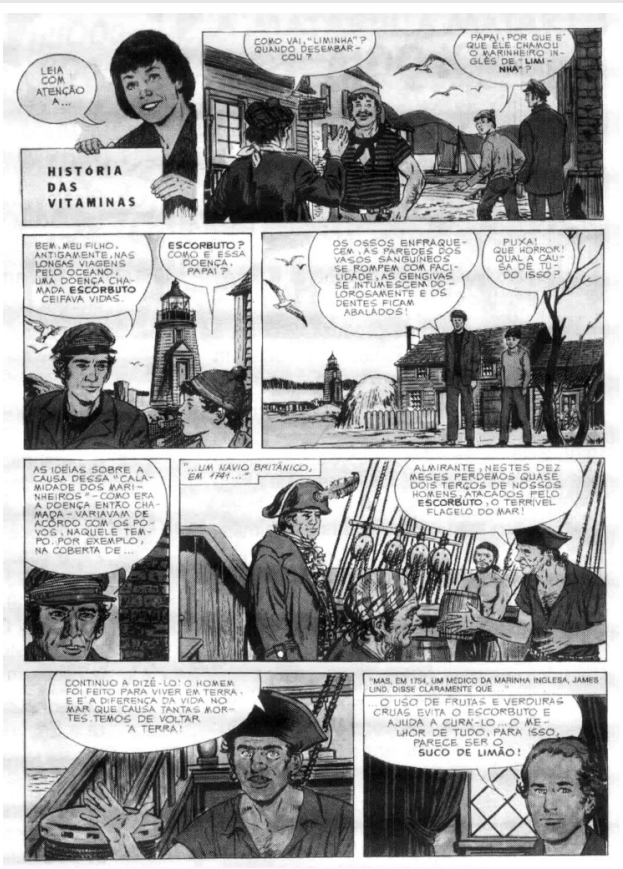

Figura 1: Página de quadrinhos desenhada nos anos 1970 por Rodolfo Zalla para livro de Ciências

No entanto, além desse uso "suavizante" dos quadrinhos nos livros didáticos e no processo avaliativo dos alunos, é possível defender outras 
aplicaçôes, mais eficientes, dos quadrinhos no processo de aprendizado (SANTOS, 200I) que possibilitam, entre outras coisas, o incentivo à leitura, o aprendizado de línguas estrangeiras, a instigação ao debate e à reflexão sobre determinado tema, ou mesmo a realização de atividades lúdicas, como a dramatização a partir de uma história em quadrinhos.

Apesar do empenho dos educadores, do aval e incentivo dos Parâmetros Curriculares Nacionais ( $\mathrm{PCNs}$ ) e da compra e distribuição, por meio do Programa Nacional Biblioteca na Escola (PNBE), de publicaçôes de quadrinhos (VERGUEIRO; RAMOS, 2009), a utilização dos quadrinhos na educação ainda necessita de reflexões que subsidiem práticas adequadas e levem a resultados concretos em relação ao aprendizado. Ter álbuns e revistas de quadrinhos disponíveis nas salas de aula ou nas bibliotecas escolares náo implica, necessariamente, no uso correto do material por parte dos professores.

É sempre bom lembrar que as histórias em quadrinhos são produzidas para públicos diferenciados (infantil, adolescente ou adulto) e, portanto, não podem ser usadas indiscriminadamente. Além disso, mesmo aquelas que se destinam apenas ao entretenimento e ao lazer, cujo conteúdo não foi gerado com a preocupação de informar ou passar conhecimento, podem ser utilizadas em ambiente didático, mas exigem um cuidado maior por parte dos professores. Por isso, este trabalho tem como objetivos apresentar reflexôes sobre a utilização de histórias em quadrinhos na educação e indicar algumas práticas pedagógicas que aproveitem melhor o potencial dos quadrinhos.

\section{Leituras de histórias em quadrinhos}

Orozco-Gomes (20II, p. I69), ao refletir sobre a vinculação das novas tecnologias de informação aos processos educativos, identifica dois tipos de racionalidades, a eficientista e a da relevância. O autor afirma que o objetivo principal da segunda - que parte do sujeito educando e de seu contexto e tem como ponto de chegada o conteúdo - "[...] náo estaria no ensino, mas no aprendizado, entendido aqui náo somente um resultado a partir de certos insumos, mas sim como processo realizado em situaçóes específicas que procuram abertamente estimulá-lo.” A apli- 
cação das histórias em quadrinhos em ambiente escolar deve ser encarada da mesma forma.

Assim, um primeiro desafio colocado ao educador é conhecer a linguagem dos quadrinhos. Nesse sentido, Ramos (2009, p. I4) afirma que "[...] ler quadrinhos é ler sua linguagem, tanto em seu aspecto verbal quanto visual (ou não verbal)”, ressaltando, ainda, que dominar essa linguagem, "[...] mesmo que em seus conceitos mais básicos, é condição para a plena compreensão da história e para a aplicação dos quadrinhos em sala de aula e em pesquisas científicas sobre o assunto."

Dessa forma, entende-se que não basta "ler" apenas o elemento textual (diálogos e textos narrativos) de uma história em quadrinhos. É preciso ir além. Segundo Groensteen (2004, p. 44), "É nas articulaçóes internas em elos de imagens que se fixa o sentido, jogando o texto, por este ângulo, frequentemente, apenas um papel complementar." É necessário, portanto, identificar os tipos de balóes (de fala, de pensamento etc.), as metáforas visuais (lâmpada acesa sobre a cabeça quando o personagem tem uma ideia, estrelas indicando dor etc.) ou as onomatopeias (representações de sons: explosão, tapa etc.).

Os formatos das histórias em quadrinhos também influenciam na maneira como elas podem ser lidas. As tiras de quadrinhos, normalmente humorísticas, desenvolvem uma história curta apresentada em uma ou, no máximo, seis vinhetas. Há uma situação inicial e uma reversão das expectativas do leitor (presente no texto ou na imagem), gerando o efeito cômico.

Já os quadrinhos publicados em revistas, álbuns ou livros ocupam um espaço maior (de uma a centenas de páginas) e apresentam uma narrativa mais complexa. A leitura de uma página de quadrinhos também é um exercício de percepção mais apurada - embora boa parte das histórias apresente uma estrutura mais tradicional, em que um quadrinho segue o outro horizontalmente e de cima para baixo - há histórias que são diagramadas de maneira diferente, forçando o leitor a descobrir a sequência certa de imagens e textos.

Um exemplo é a história $A$ guerra do reino Divino (Figura 2), criada por Jô Oliveira (200I): no alto, sobre a imagem dos soldados avançando com armas em punho, quatro vinhetas invadem o espaço (o oficial gritando "Fogo!", o canhão atirando, a bala rasgando o corpo do beato e o povo percebendo a sua morte); no meio da página uma vinheta horizontal 
apresenta o desespero das pessoas com o avanço da polícia e, na parte de baixo, são usadas duas vinhetas, sendo que uma delas está sem o requadro (fio que contorna o quadrinho). Do ponto de vista temático, é possível relacionar o conteúdo à repressão sofrida pelos habitantes de Canudos e à religiosidade popular do Nordeste. Já no que concerne à estética, o estilo gráfico do autor assemelha-se aos desenhos da literatura de cordel, típica da cultura nordestina.

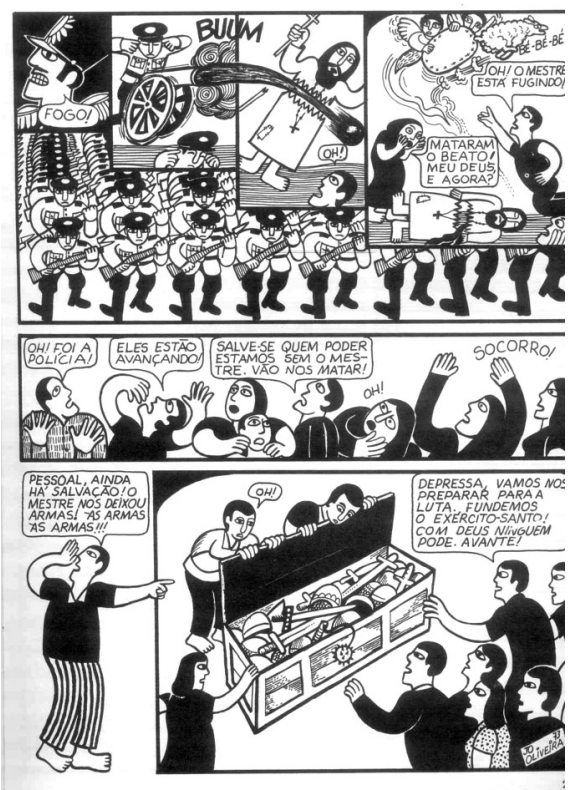

Figura 2: A história A guerra do reino Divino mistura quadrinhos e literatura de cordel

Desse raciocínio, é possível desenvolver três atividades práticas. A primeira é a leitura de uma história em quadrinhos para identificar sua linguagem e a disposição de seus elementos narrativos. O professor também pode retirar os textos dos balóes e solicitar aos estudantes que elaborem novos diálogos, trabalhando a articulação texto-imagem. Outro exercício, que pode ser conduzido conjuntamente com docentes de Artes e de Língua Portuguesa, é a criação de histórias em quadrinhos pelos próprios alunos, utilizando cartolina ou sulfite. Individualmente ou em grupo, eles 
são orientados a desenvolver o argumento (tema, personagens, tempo e espaço da narrativa etc.) e o roteiro (quais açôes e diálogos devem ocupar cada vinheta) da história e a fazer a arte (desenho e colorização). Ao final, pode-se organizar uma exposição dos trabalhos na escola, que, inclusive, servirá de incentivo a outros estudantes. A esse respeito, Edgar Franco (20II, p. II5-II6) indica técnicas alternativas para a criação de quadrinhos nas escolas, com fotografias (fotonovela) e com softwares gratuitos disponíveis na internet.

\section{Quadrinhos e literatura}

Embora as histórias em quadrinhos impliquem na leitura, não é correto dizer que elas constituem uma forma literária. No entanto, por compartilharem elementos narrativos típicos do texto literário, os quadrinhos têm-se prestado para a adaptaçáo de contos ou de romances. Lielson Zeni (2009, p. I28) identifica a origem da quadrinização da literatura:

Ela começou no final da primeira metade do século passado, com a coleção Classics Illustrated, título da revista norte-americana voltada para a publicação de clássicos da literatura mundial em quadrinhos. Inicialmente chamada de Classic Comics, a revista surgiu em I94I e durou até I97I, tornando-se cultuada na área e abrindo espaço para quadrinizaçóes de romances [...]

No Brasil, a Editora Brasil-America Ltda. (EBAL) publicou por mais de uma década a revista Edição Maravilhosa e, por algum tempo, o título Álbum Gigante, ambos dedicado a adaptaçóes de obras literárias para os quadrinhos. Além de traduzir o material da Classics Illustrated, essas publicaçóes também ofereciam ao leitor quadrinizaçóes de romances brasileiros, a exemplo de A escrava Isaura, de Bernardo Guimarães (1954), O Guarani, de José de Alencar (1950), entre outros. No início do século $\mathrm{XXI}$, com a compra de publicações de quadrinhos por meio do PNBE, várias editoras passaram a produzir álbuns com quadrinizaçôes literárias (VERGUEIRO; RAMOS, 2009). 
O mais importante, entretanto, não é a qualidade da transcodificação da literatura para a narrativa gráfica sequencial, mas a maneira como o educador emprega esse material, que não deve substituir o texto literário. Nesse sentido, Zeni (2009, p. I3I, grifo do autor) adverte:

Mas, tratada sob o ponto de vista paradidático, é bastante importante recuperar a leitura em relação em relação à obra original proposta pela adaptação, pois nosso foco de interesse está no original. A adaptaçáo aqui é um apoio, uma ferramenta, uma outra leitura. E não podemos nos esquecer disso: a adaptação traz apenas uma leitura da obra original e não a solução ou a interpretação definitiva para ela.

A história em quadrinhos, por seu caráter icônico, acrescenta informaçôes visuais ao elemento verbal. Em O alienista, de Machado de Assis, versão realizada pelos artistas Fabio Moon e Gabriel Bá (2007), além da história originalmente concebida pelo Bruxo do Cosme Velho, o leitor também encontra dados sobre o comportamento social no final do século XIX. Na Figura 3, por exemplo, vê-se um garoto negro acompanhando a senhora branca e segurando seu guarda-chuva, o que evidencia a divisáo racial existente na época.

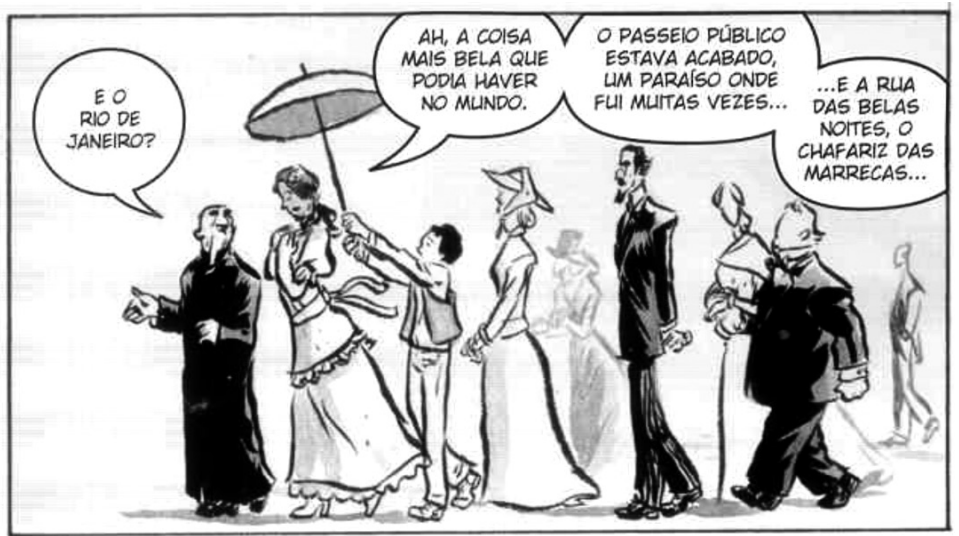

Figura 3: A adaptaçáo de $O$ Alienista mostra o vestuário e os costumes do século XIX 
Por meio de sua iconicidade, a história em quadrinhos pode oferecer ao leitor elementos que o texto literário apenas descreve ou não apresenta: na mesma adaptação, podem ser vistos o vestuário (Figura 3), o mobiliário, a decoraçáo das casas e o estilo arquitetônico daquele período (Figura 4). Cabe ao professor ressaltar esses aspectos presentes em narrativas quadrinhísticas, para que a leitura extrapole os limites do aspecto verbal e seja enriquecida pelo visual.

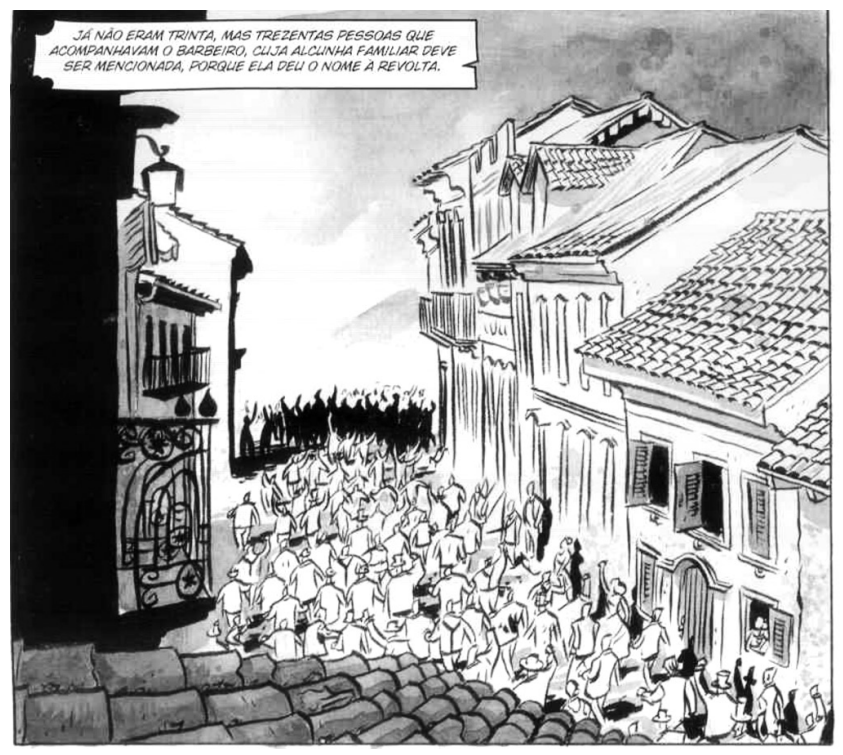

Figura 4: Elementos arquitetônicos do século XIX são cenários da história em quadrinhos

\section{$4 \quad$ Outras áreas de ensino}

As aplicações dos quadrinhos no processo de aprendizado não devem ser restritas às adaptaçóes literárias. Por ser o resultado de um processo artístico, os quadrinhos levam à compreensão de técnicas e conceitos estéticos da área de Artes. Para Alexandre Barbosa (2004, p. I3I)

Todos os principais conceitos das artes plásticas estão embutidos nas páginas de uma história em quadrinhos. Assim, para 
o educador, as HQs podem vir a ser uma poderosa ferramenta pedagógica, capaz de explicar e mostrar aos alunos, de forma divertida e prazerosa, a aplicação prática de recursos artísticos sofisticados, tais como perspectiva, anatomia, luz e sombra, geometria, cores e composição.

De fato, considerada a Nona Arte, a história em quadrinhos possui uma perspectiva estética que deve ser considerada pelos professores. Nesse sentido, no entender de Will Eisner (1989, p. 5), ela é "[...] um veículo de expressão criativa [...] uma forma artística e literária que lida com a disposição de figuras ou imagens e palavras para narrar uma história ou dramatizar uma ideia." Assim, o conteúdo expressivo é relevante na leitura dos quadrinhos, acrescentando componentes artísticos à narrativa. $\mathrm{Na}$ adaptação de textos escritos por Franz Kafka, por exemplo, o artista estadunidense Peter Kuper (2008) empregou técnicas do Expressionismo - movimento que envolveu as artes plásticas, o teatro e o cinema, do final do século XIX até a década de 1920 -, como o contraste entre luz e sombra e a deformação, para ressaltar o clima de absurdo e de repressão retratado pelo autor tcheco.

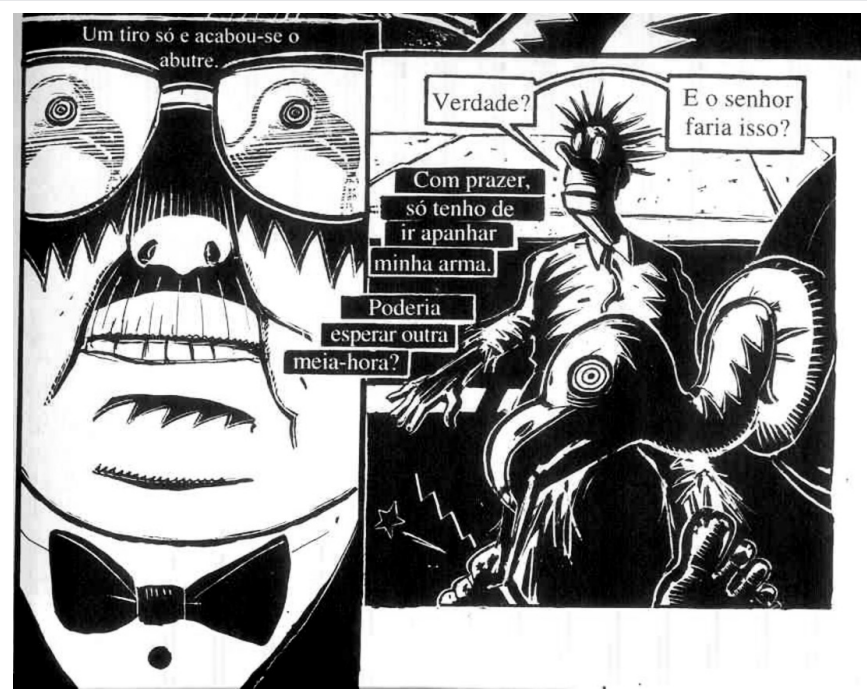

Figura 5: $O$ abutre, de Franz Kafka, desenhada em estilo expressionista 
Para as aulas de História há muitas narrativas em quadrinhos que podem ser utilizadas pelos professores. Neste rol enquadram-se tanto as ficcionais - como é o caso de Adeus, chamigo brasileiro, de André Toral (1999), história ambientada na Guerra do Paraguai, como aquelas baseadas em fatos reais - das quais Maus, de Art Spiegelman (2005), que aborda o extermínio de judeus na Segunda Guerra Mundial, é um exemplo de destaque. Para Túlio Vilela (2004, p. I09-I Io), o uso dos quadrinhos pode ser feito de diferentes maneiras: para ilustrar ou fornecer uma ideia de aspectos da vida social de comunidades do passado; como registros da época em que foram produzidos e como ponto de partida de discussóes de conceitos da História. Eventos pouco conhecidos são temas de álbuns de quadrinhos, sendo um bom exemplo Chibata! (Figura 6), de Olinto Gadelha e Hemeterio (2008), sobre a Revolta da Chibata, acontecida em I9Io, quando marinheiros negros amotinaram-se no Rio de Janeiro para forçar o governo a abolir os castigos físicos aplicados por oficiais brancos nos navios.

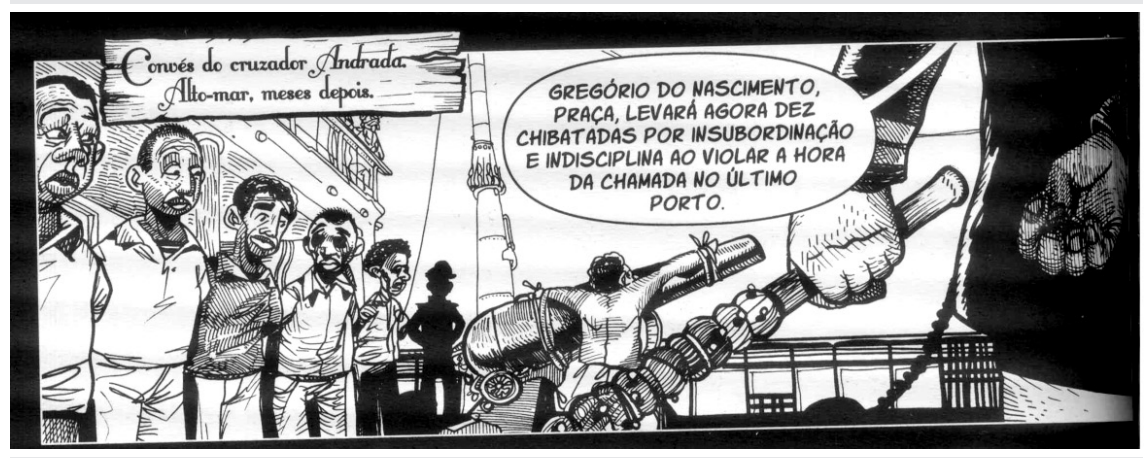

Figura 6: Quadrinhos reconstituem a Revolta da Chibata

Os quadrinhos também propiciam a divulgação científica e a abordagem de questóes inerentes à ciência, que podem subsidiar as aulas: a trajetória do filósofo inglês Bertrand Russell e as bases da Lógica são temas do livro de quadrinhos Logicomix, realizado por professores gregos (DOXIADIS; PAPADIMITRIOU; PAPADATOS, DI DONNA, 20Io). A constituição e o desenvolvimento da Física, assim como a vida de seus principais teóricos, são tratados no álbum Ombros de gigantes (Figura 7), 
dos professores Annibal Hetem Junior e Jane Gregorio-Hetem e o desenhista Marlon Tenório.

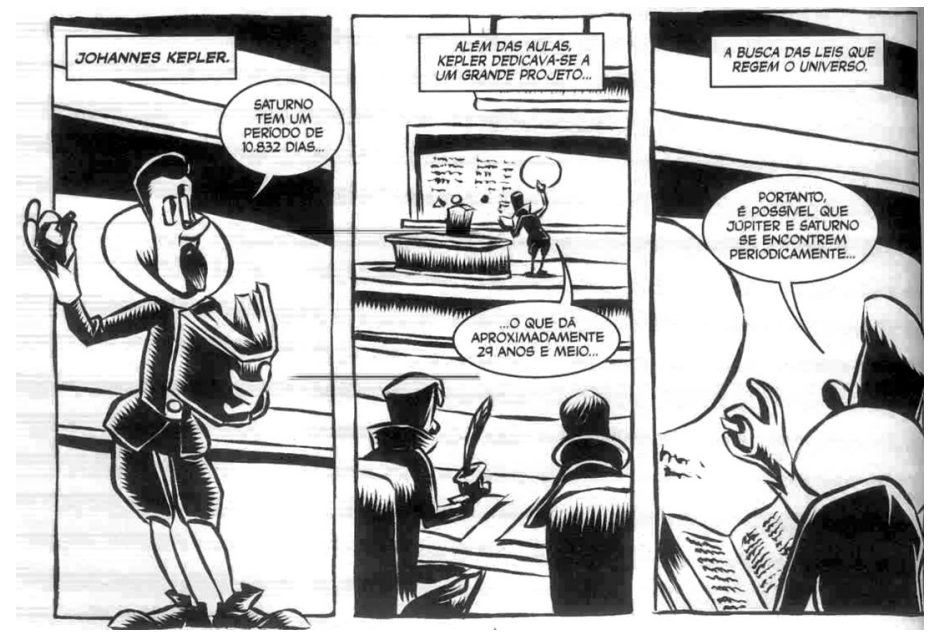

Figura 7: História apresenta a evolução da Física

No caso das cartilhas científicas quadrinizadas, Márcia Mendonça (20I0, p. I I 8), analisando aquelas voltadas para a área da saúde constatou que a trama dessas publicaçôes em geral abarca situaçôes de perigo, envolvendo heróis e vilóes, para apresentar a prevenção ou o tratamento de doenças específicas. A conclusão semelhante chegou Waldomiro Vergueiro (2009, p. 97) ao analisar as histórias em quadrinhos para educação popular no Brasil, identificando, inclusive, uma estrutura típica dessas publicações:

I) há uma situação-problema - ocorre uma calamidade como resultado de uma falta de atenção coletiva ou governamental com respeito a certas precauções elementares quanto à preservaçáo de recursos naturais, um personagem se mostra desatento ou reage diretamente contra um comportamento desejado, assumindo uma atitude anti-social -, que tem suas raízes e soluçôes explicadas por um dos personagens da história;

2) os protagonistas são colocados em uma situação em que entram em contato com as peculiaridades de um determinado 
problema, ambiente ou instituição, sendo conduzidos por um personagem em direção ao conhecimento das principais características daquele objeto - em uma das histórias, os protagonistas são contratados para elaborar uma produção cinematográfica sobre uma determinada instituição;

3) um personagem é criado com o objetivo específico de explicar as características de um ambiente, situação ou empresa para os leitores.

\section{Consideraçóes finais}

Com base nas questóes tratadas neste texto, pode-se asseverar que as histórias em quadrinhos podem ter um papel considerável no processo educativo, mas é preciso que educadores e estudantes saibam como empregá-las. É necessária uma triagem do material, separando o que é apropriado às diferentes faixas etárias ou que contém informaçóes relevantes. Empreender atividades práticas a partir das histórias torna as aulas mais dinâmicas e o aprendizado mais prazeroso. E, por fim, é importante lembrar que a leitura de quadrinhos é complexa e não deve se restringir ao texto ou ao enredo; ler e perceber os recursos da linguagem, da estética e da narrativa das narrativas quadrinizadas amplia as significaçóes que podem ser extraídas de seu conteúdo.

\section{Referências}

BARBOSA, Alexandre. Os quadrinhos no ensino de Artes. In: RAMA, Angela; VERGUEIRO, Waldomiro (Org.). Como usar as histórias em quadrinhos na sala de aula. São Paulo: Contexto, 2004. p. I3I-I 49.

BEATY, Bart. Fredric Wertham and the critique of mass culture (Fredric Wertham e a critica da cultura de massa). Jackson: University Press of Mississippi, 2005.

CARVAlHO, DJota. A educação está no gibi. Campinas: Papirus, 2006.

DOXIADIS, Apostolos; PAPADIMITRIOU, Christos H.; PAPADATOS, Alecos; Di DONNA, Annie. Logicomix: uma jornada épica em busca da verdade. São Paulo: Martins Fontes, 2010. 
EDIÇÃO Maravilhosa, Rio de Janeiro, EBAL, n. 24, jun. I950.

EDIÇÃO Maravilhosa, Rio de Janeiro, EBAL, n. 92, set. 1954.

EISNER, Will. Quadrinhos e arte sequencial. São Paulo: Martins Fontes, I989.

FRANCO, Edgar. Criando histórias em quadrinhos com técnicas alternativas. In: SANTOS NETO, Elydio; SILVA, Marta Regina Paulo da (Org.). Histórias em quadrinhos \& Educação: formação e prática docente. São Bernardo do Campo: UMESP, 20II. p. I07-I25.

FREMION, Yves; JOUBERT, Bernard. Images interdites. Paris: Editions SyrosAlternatives, cr989.

GADELHA, Olinto; HEMETERIO. Chibata. São Paulo: Conrad, 2008.

GROENSTEEN, Thierry. História em quadrinhos: essa desconhecida arte popular. Joáo Pessoa: Marca de Fantasia, 2004.

HETEM JÚNIOR, Annibal; Gregorio-Hetem, Jane; TENÓRIO, Marlon. Ombros de gigantes. São Paulo: Devir, 2004.

KUPER, Peter. Desista (Franz Kafka adaptado por Peter Kuper). São Paulo: Conrad, 2008.

MOON, Fábio; BÁ, Gabriel. O alienista, de Machado de Assis. Rio de Janeiro: Agir, 2007.

MENDONÇA, Márcia. Ciência em quadrinhos: imagem e texto em cartilhas educativas. Recife: Bagaço, 20 ıo.

NYBERG, Amy Kiste. Seal of approval: the history of the comics code. Jackson:

University Press of Mississippi , 1998.

OLIVEIRA, Jô. A guerra do Divino. São Paulo: Hedra, 200 .

OROZCO-GOMES, Guillermo. Comunicação, educação e novas tecnologias: tríade do século XXI. In: CITELLI, Adílson Odair; COSTA, Maria Cristina (Org.). Educomunicação: construindo uma nova área de conhecimento. São Paulo: Paulinas, 2OII.

RAMOS, Paulo. A leitura dos quadrinhos. São Paulo: Contexto, 2009.

SANTOS, Roberto Elísio dos. Aplicaçôes da história em quadrinhos. Comunicação \& Educação, São Paulo, ECA-USP, n. 22, p. 46-51, set./dez. $200 \mathrm{I}$.

SPIEGELMAN, Art. Maus: a história de um sobrevivente. São Paulo: Companhia das Letras, 2005 .

TORAL, André. Adeus Chamigo brasileiro: uma história da Guerra do Paraguai. São Paulo: Companhia das Letras, I999. 
VERGUEIRO, Waldomiro. Quadrinhos e educação popular no Brasil: consideraçóes à luz de algumas produçôes nacionais. In: VERGUEIRO, Waldomiro; RAMOS, Paulo (Org.). Muito além dos quadrinhos: análises e reflexóes sobre a 9a Arte. São Paulo:

Devir, 2009. p. 83-102. .; RAMOS, Paulo (Org.). Quadrinhos na educação: da rejeição à prática. São

Paulo: Contexto, 2009.

VILELA, Túlio. Os quadrinhos na aula de História. In: RAMA, Angela;

VERGUEIRO, Waldomiro (Org.). Como usar as histórias em quadrinhos na sala de aula. Sáo Paulo: Contexto, 2004. p. I05-I29.

ZALLA, Rodolfo. A arte de Rodolfo Zalla. São Paulo: Ed. D`Arte, I992.

ZENI, Lielson. Literatura em quadrinhos. In: VERGUEIRO, Waldomiro; RAMOS, Paulo (Org.). Quadrinhos na educação: da rejeiçáo à prática. Sáo Paulo: Contexto, 2009. p. $127-\mathrm{I} 56$.

Recebido em 9 mar. 2012 / Aprovado em 24 abr. 2012

\section{Para referenciar este texto}

SANTOS, R. E.; VERGUEIRO, W. Histórias em quadrinhos no processo de aprendizado: da teoria à prática. EccoS, São Paulo, n. 27, p. 8I-95. jan./abr. 2012. 
